\title{
Treatment of Growth Hormone Deficiency in Very Young Children
}

\author{
Jean-Claude Carel ${ }^{a}$ Frédéric Huet ${ }^{b}$ Jean-Louis Chaussain ${ }^{a}$ \\ a Department of Paediatric Endocrinology and INSERM U561, Groupe hospitalier Cochin-Saint Vincent de Paul and

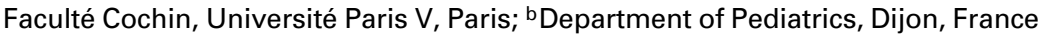

\section{Key Words}

Growth hormone - Growth hormone deficiency • Infants · Growth hormone therapy · Hypopituitarism • Insulin-like growth factor I - Multiple pituitary hormone deficiencies - Gonadotropin deficiency before we can claim that we have completely normalized their condition. In particular, careful assessments of the psychological and neurodevelopmental outcomes will become necessary in order to evaluate the 'final results' of endocrine replacement therapies.

Copyright $\odot 2003$ S. Karger AG, Basel

\begin{abstract}
Growth hormone $(\mathrm{GH})$ deficiency is a rare disease in very young children and a challenge to the physician in terms of clinical recognition, diagnosis and treatment. Here, we review the available information regarding substitution of $\mathrm{GH}$ and other pituitary hormones in this patient group. Our results confirm the severity of the clinical presentation and the rapid loss of height (measured in standard deviation scores) in hypopituitary patients that occurs early in life. $\mathrm{GH}$ therapy induces a rapid catch-up of growth and the frequency of injections appears to be a more important determinant than the size of the dose itself. Long-term results are available in only a small percentage of patients, yet they show a favourable auxological outcome, compared with target height or historical height data from patients with severe hypopituitarism. In conclusion, although tremendous progress has been made in providing for those children with early onset and severe hypopituitarism, there is still a long way to go
\end{abstract}

\section{Introduction}

Growth hormone $(\mathrm{GH})$ deficiency is rare in very young children and is a challenge to the physician in terms of its clinical recognition, diagnosis and treatment. Its clinical manifestations can be misleading as growth retardation is generally not the presenting symptom. The diagnosis of GH deficiency (GHD) in infants is compounded by the difficulties in performing dynamic tests and the lack of high-quality, normative data in children younger than 2 years. Treatment with $\mathrm{GH}$ is usually administered at a similar dose and frequency to that given to older children and generally has little similarity to the natural hormonal secretion in this age group.

Here, complementing the paper by Dr Ogilvy-Stuart on specific issues regarding the diagnosis of GHD in very young children [1], we will review the current knowledge on $\mathrm{GH}$ treatment in infants.

\section{KARGER}

Fax + 41613061234

E-Mail karger@karger.ch

www.karger.com
(C) 2003 S. Karger AG, Basel

0301-0163/03/0607-0010\$19.50/0

Accessible online at:

www. karger.com/hre
Prof. J.-C. Carel

Paediatric Endocrinology and INSERM U561

Groupe hospitalier Cochin-Saint Vincent de Paul

82 avenue Denfert Rochereau, FR-75014 Paris (France)

E-Mail carel@cochin.inserm.fr 


\section{Physiology of GH and IGF-I Secretion in Very Young Children: What Is the Replacement Dose for This Age Group?}

GH therapy in patients with GHD aims to replace the physiological secretion of the hormone $[2,3]$, but a full physiological replacement is not currently feasible for several reasons. First, $\mathrm{GH}$ is secreted in a pulsatile mode whereas daily administrations of GH provide wide bursts of the hormone. Second, GH secretion varies with age and little is known about the physiological variation in $\mathrm{GH}$ levels in infants. Finally, inter-individual variations of $\mathrm{GH}$ secretion are rarely taken into account when the drug is prescribed, although it might be expected that a number of individuals may need very variable amounts of $\mathrm{GH}$, depending on the influence of genetic or environmental factors on their responsiveness.

The traditional amount of GH prescribed for GHD is $25-50 \mu \mathrm{g} / \mathrm{kg} / \mathrm{day}$. This amount varies in Europe (25$35 \mu \mathrm{g} / \mathrm{kg} / \mathrm{day})$ and in the USA $(25-43 \mu \mathrm{g} / \mathrm{kg} / \mathrm{day})$. If this dose range is applied to a $5-\mathrm{kg}$ baby, however, the range converts to $125-250 \mu \mathrm{g} / \mathrm{day}$, but most pen devices have increments of $100 \mu \mathrm{g}$. Although syringes can be used for patients in this age group, allowing a more refined optimization of the treatment dose, most parents prefer to use pens.

The daily production of GH has been estimated to be approximately $16-38 \mu \mathrm{g} / \mathrm{kg} / \mathrm{day}$ [2] and varies with age: $16-20 \mu \mathrm{g} / \mathrm{kg} /$ day in pre-pubertal children and 20-38 $\mu \mathrm{g} /$ $\mathrm{kg} /$ day in pubertal adolescents or young adults. No similar value can be extracted from the literature for infants. However, newborns and, to a lesser degree, infants are generally 'GH resistant'. This age group is characterized by plasma levels of GH and insulin-like growth factor I (IGF-I) that are high and low, respectively. At mid-gestation, plasma levels of GH in the fetus are markedly elevated, averaging $30 \mathrm{ng} / \mathrm{ml}$ on a random sample, while IGF-I levels are low, averaging $20 \mathrm{ng} / \mathrm{ml}$ [4]. In contrast, in samples taken around the 35th week of gestation, GH levels have decreased by approximately $50 \%$ while IGF-I levels have increased almost four-fold [4]. In a study performed in newborns, GH secretion was elevated compared with that in older children [5] and varied with feeds with a peak $60 \mathrm{~min}$ after food [6]. Fasting GH concentrations were higher in babies born small for gestational age than in babies with an average weight for gestational age. IGF-I levels tend to mirror this trend, with values being lower in small- versus normal-weight babies. However, no direct relationship between GH and IGF-I levels was found in this study [6]. In a series of 59 normal infants with a median age of 98 days (range, 13-349 days), the mean fasting level of $\mathrm{GH}$ was $10.4 \mathrm{ng} / \mathrm{ml}$ (range, 0.3$42 \mathrm{ng} / \mathrm{ml}$ ) and was inversely correlated with age [7]. In contrast to the response observed in older children, the response of GH to glucagon in the infants was very limited (an increase of approximately 20\%), while glucagon stimulated plasma glucose and insulin very significantly. Similarly, using urinary GH measurements in a large series of children, Quattrin et al. [8] showed that the production of $\mathrm{GH}$ (expressed in $\mathrm{ng} / \mathrm{kg}$ ) decreased approximately 15 -fold between infancy and childhood. They also identified a trend for higher values in pre-term versus atterm infants. This trend does not seem to be caused by specific regulation of circulating $\mathrm{GH}$ isoforms because the fractions of $20-$ and $22-\mathrm{kDa} \mathrm{GH}$ are stable with time throughout childhood [9]. In contrast with the decrease of GH levels in plasma or urine during childhood, plasma IGF-I levels increase with age, in particular in infants [10, 11]. Free IGF-I levels paralleled total plasma IGF-I levels in this age group [12].

In conclusion, throughout infancy, there is a progressive decline in GH and a progressive increase in IGF-I secretion, suggesting that there is an increase in GH 'sensitivity' during this period. The description of this specific pattern is still incomplete, however, and the mechanisms underlying this adaptation are not yet known. Nevertheless, these physiological observations should help us to optimize the substitution regimen with GH during infancy and it would seem reasonable to evaluate schemes in which this pattern is mimicked. The general assumption of the daily requirements of GH extrapolated from normative values established in older children is probably false.

\section{Clinical Characteristics and Short-Term \\ Response to Treatment in Patients with GHD Identified during the First Year of Life}

The evaluation of GH therapy in children within this age range is particularly difficult because of the rarity of the disease. There are few reports combining multicentre data acquired over extended periods of time with recent and more old-fashioned treatment regimens.

We have been able to analyse a multicentre series of 59 patients, recruited across France through the Association France-Hypophyse [13], treated with GH for GHD before the age of 1 year. The baseline characteristics of these children are presented in table 1 . The mean age at diagnosis was around 6 months, but was younger in boys than in 


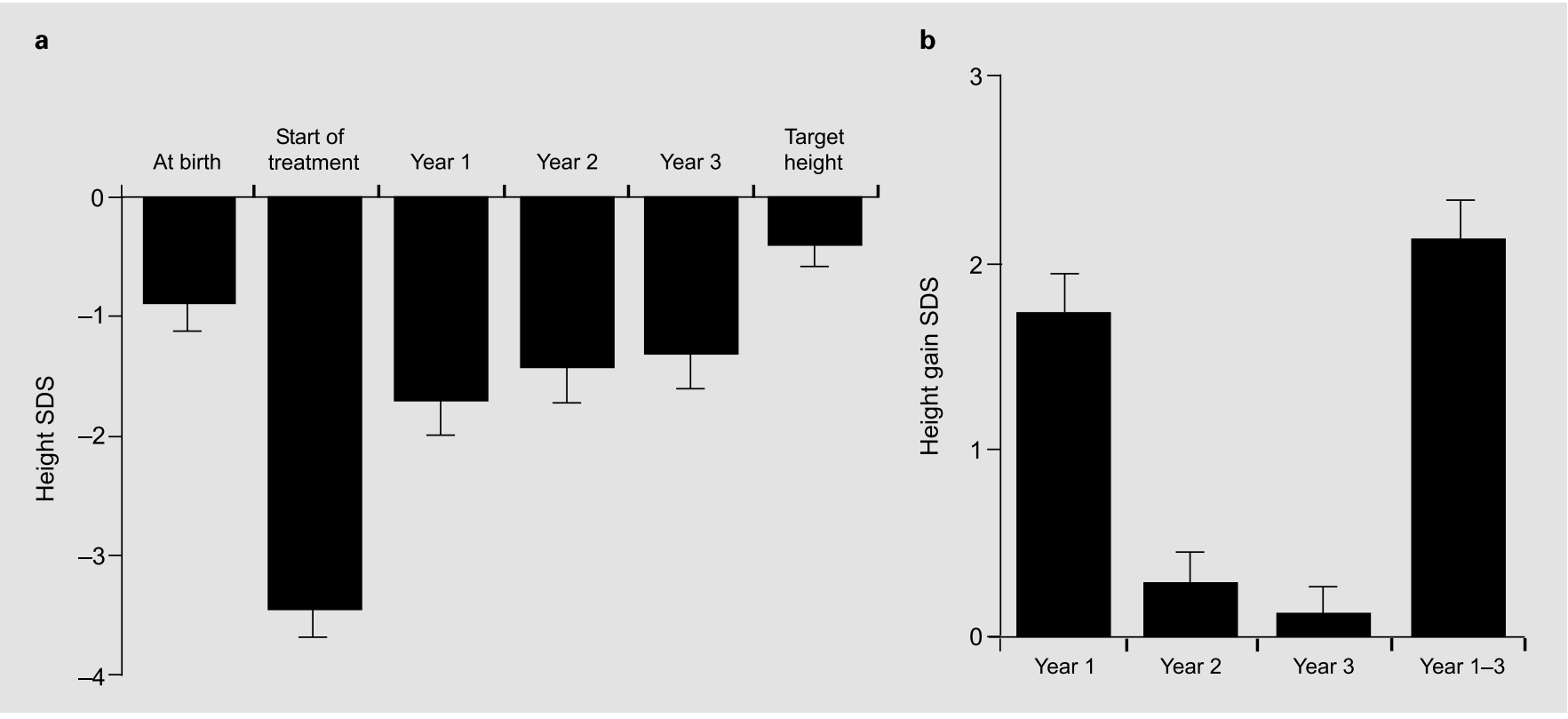

Fig. 1. Height SDS (a) and height gain SDS (b) in 59 patients with GHD treated before the age of 1 year. Reproduced, with permission, from Huet et al. [13]: ${ }^{\odot}$ The Society of the European Journal of Endocrinology.

Table 1. Baseline characteristics of the patients receiving GH therapy for GHD. Reproduced, with permission, from Huet et al. [13]: ${ }^{\odot}$ The Society of the European Journal of Endocrinology

\begin{tabular}{lllc}
\hline & $\begin{array}{l}\text { All } \\
(\mathrm{n}=59)\end{array}$ & $\begin{array}{l}\text { Boys } \\
(\mathrm{n}=33)\end{array}$ & $\begin{array}{l}\text { Girls } \\
(\mathrm{n}=26)\end{array}$ \\
\hline Term, weeks & $39.9 \pm 1.6$ & $39.8 \pm 1.7$ & $40.0 \pm 1.5$ \\
Birth length, SDS & $-0.9 \pm 1.4[-5.5 ;+1.4]$ & $-0.8 \pm 1.4[-5.5 ;+0.9]$ & $-1.1 \pm 1.3[-3.7 ;+1.4]$ \\
Age, months & $5.8 \pm 3.8[0.3 ; 12.0]$ & $4.6 \pm 3.4[0.5 ; 10.0]$ & $6.8 \pm 3.9 *[0.3 ; 12.0]$ \\
Target height, SDS & $-0.4 \pm 0.8$ & $-0.2 \pm 0.8$ & $-0.6 \pm 0.9$ \\
Hypoglycaemia, $\mathrm{n}(\%)$ & $50(85 \%)$ & $29(88 \%)$ & $21(81 \%)$ \\
Seizures, $\mathrm{n}(\%)$ & $14(24 \%)$ & $8(24 \%)$ & $6(23 \%)$ \\
Micropenis, $\mathrm{n}(\%)$ & & $17(52 \%)$ & $7(27 \%)$ \\
Jaundice, $\mathrm{n}(\%)$ & $25(42 \%)$ & $18(55 \%)$ & $57.4 \pm 6.5[48.0 ; 74.5]$ \\
Height, cm & $56.7 \pm 6.1[45.3 ; 74.5]$ & $56.2 \pm 5.9[45.3 ; 66]$ & $-3.6 \pm 2.0[-6.4 ;+1.4]$ \\
Height, SDS & $-3.5 \pm 1.9[-7.0 ;+1.6]$ & $-3.4 \pm 1.9[-7.0 ;+1.6]$ & $1.6 \pm 1.8[0.0 ; 6.2]$ \\
Maximum stimulated GH, $\mu \mathrm{g} / 1$ & $2.2 \pm 2.8[0.0 ; 8.0]$ & $2.8 \pm 3.3[0.0 ; 8.0]$ & 3 \\
Isolated GHD, $\mathrm{n}$ & 9 & 6 & 20 \\
Thyrotropin deficiency, $\mathrm{n}$ & 45 & 25 & 17 \\
Corticotropin deficiency, $\mathrm{n}$ & 38 & 21 & \\
\hline
\end{tabular}

Means \pm SD [and range] are shown. $* p<0.01$

girls because of the easier and, therefore, earlier recognition of micropenis or cryptorchidism in boys. The majority of patients $(83 \%)$ had additional pituitary hormonal deficiencies and the frequency of clinical manifestations associated with multiple pituitary hormone deficiencies was quite striking, in particular jaundice and hypoglycaemia. One other important feature is the growth pattern of these children (table 1 and fig. 1): the birth length was, on average, slightly below the mean for normal birth length at around -1 standard deviation score (SDS); in 


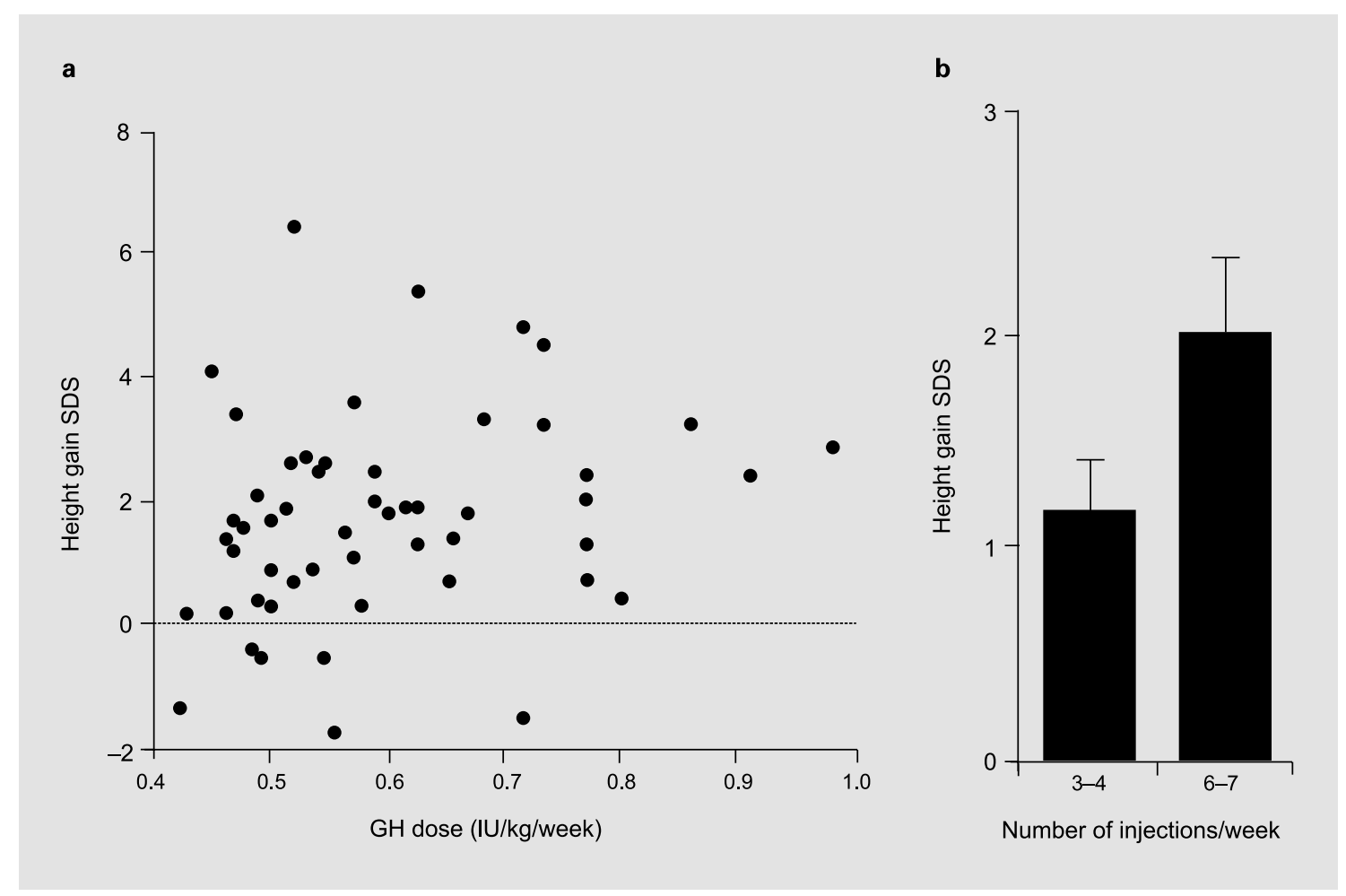

Fig. 2. Influence of GH dose (a) and number of injections per week (b) on height gain during the first year of treatment.

contrast, at the time of diagnosis, height expressed in SDS was an average of -3.5 , indicating that these children had lost an average of $2.5 \mathrm{SD}$ of height in 6 months. The growth failure, however, was not the presenting symptom in most cases and was an incidental finding during evaluation for other presenting symptoms.

GH therapy was administered at an average dose of 0.5 $\pm 0.15 \mathrm{IU} / \mathrm{kg} /$ week $(0.024 \pm 0.01 \mathrm{mg} / \mathrm{kg} /$ day $)$ during the first 2 years. As the data were collected retrospectively from the mid 1980s, a significant proportion of patients $(51 \%)$ were treated with 3 or 4 injections per week, while the rest $(49 \%)$ were treated daily or 6 times a week. Figure $1 \mathrm{~b}$ shows that the start of treatment induced a rapid catch-up of growth averaging 1.7 SD during the first year. Height SDS continued to increase, although to a lesser extent, during the second and third years. Two therapeutic factors were analysed for their ability to explain the variability of growth rate during the first year. Height SDS at baseline, as expected, was strongly correlated (negatively) with height gain during the first 2 years, accounting for the regression towards the mean and a higher potential for catch-up of growth in patients with severe growth retardation. We then tested, by analysis of variance, two thera- peutic explanatory variables: the GH dose expressed in $\mathrm{IU} / \mathrm{kg} /$ week and the number of injections, using height SDS at baseline as a covariate. Interestingly, the number of injections correlated significantly with the 2-year catchup growth rate, whereas the size of dose was not significantly associated (fig. 2). This correlation is shown in figure 3 , in which growth can be seen to continue during the second and third years of treatment in patients treated with 6 or 7 injections per week, whereas the height SDS can be seen to plateau after the end of the first year in patients treated with 3 or 4 injections per week.

Other studies have addressed similar issues. Boersma et al. [15] analysed the outcome in 26 patients who were less than 3 years of age at the start of treatment ( 7 with isolated GHD and 19 with multiple pituitary hormone deficiencies). The average dose used was $15 \mathrm{IU} / \mathrm{m}^{2} /$ week ( $\sim 0.5 \mathrm{IU} / \mathrm{kg} /$ week). They observed a similar effect with injection frequency as there was a much stronger catch-up of growth of $1.4 \pm 1.1 \mathrm{SD}$ versus $2.7 \pm 1.6 \mathrm{SD}$ in patients receiving 2-4 versus 6 or 7 injections per week after 4 years of treatment, respectively. As in our findings, the dose itself was not a predictor of catch-up growth. In the study by Rappaport et al. [14], 49 GH-deficient children 
Fig. 3. Influence of the number of injections per week on gain in height (SDS) (a) and height SDS (b) during the first 3 years of treatment.

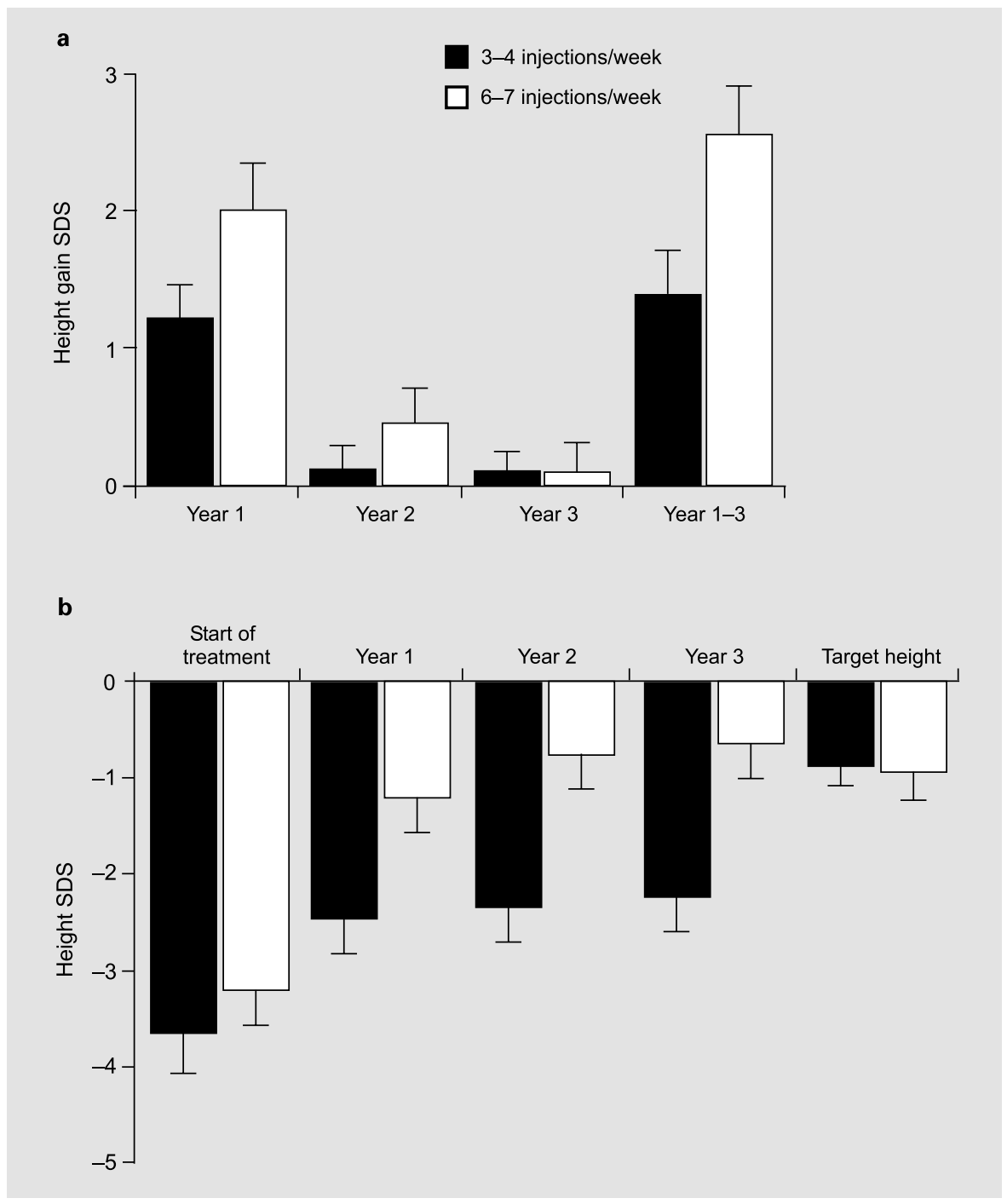

whose treatment began before the age of 3 years were selected for treatment with $\mathrm{GH}$ at a dose of $0.6 \mathrm{IU} / \mathrm{kg} /$ week $(0.03 \mathrm{mg} / \mathrm{kg} / \mathrm{day})$ in 6 or 7 injections per week. Details of the associated deficiencies were not provided, and nor was the severity of GHD. A subgroup of patients had height within normal limits at the start of the treatment and their height increased to a mean of 0 SDS after the first year of treatment (group A). Patients with growth retardation at inclusion (-3.6 SDS) had catch-up growth during the first 4 years of treatment, but reached a plateau at around -0.8 SDS, which was significantly below the mean and below target height (fig. 4). In an Italian collaborative study of 16 patients whose therapy began during the first year of life [16], the findings were remarkably similar, with an initial catch-up of growth and a plateau at around -1 SDS, a value significantly lower than target height.

Altogether, these data clearly demonstrate that the results are suboptimal in this patient population, whether as a result of the treatment regimen, compliance problems, or intrinsic characteristics of the patients (optimization of other hormonal replacements, role of gonadotropin deficiency). These observations, together with the induction of GH secretion by feeding in newborns, would suggest that the use of multiple daily injections to provide optimal GH replacement in infancy should be evaluated. It is clear, however, that practical issues limit the applicability of these theoretical considerations. Another avenue for exploration is to increase the size of the dose, although the retrospective data analysed suggest that dosing, in the 
range explored so far, does not play a major role. Prospective trials with strong emphasis on safety and IGF-I monitoring would allow the evaluation of multiple dose regimens in this patient population.

\section{Outcome Measures of GH Treatments in Very Young Children}

Growth response to $\mathrm{GH}$ therapy remains the major measure of outcome in children with GHD. There is, however, a need to address other therapeutic issues, in particular in very young children. Hypoglycaemia is a frequent feature in infants with hypopituitarism (85\% in our series) and can be severe enough to cause seizures in 1 out of 4 children. Long-term sequelae of hypoglycaemia in the neonatal period and infancy in children with neonatal hyperinsulinism are well known [17-19], but little is known of the neuropsychological development of children treated for early hypopituitarism. When the diagnosis is made, a few fasting or capillary plasma glucose measurements are generally taken, but little emphasis is placed on the monitoring of glycaemia, especially in situations of limited carbohydrate intake, such as intercurrent illnesses. A preliminary report of the use of the continuous glucose monitoring system in children with neonatal hypopituitarism has yielded promising results [20]. Although one of the limitations of the continuous glucose monitoring system is its low threshold, making it unreliable when plasma glucose falls below $60 \mathrm{mg} / \mathrm{dl}$, the device has allowed for the identification of unsuspected low glucose values in untreated, as well as in treated, infants. A more thorough attention to these aspects is, therefore, probably needed in the future.

Plasma IGF-I levels should also be carefully monitored in these children as it is expected that adequate treatment will normalize both total IGF-I and other components of the IGF-I complex (IGF-binding protein 3, acid-labile subunit). No specific report is available for this age group and so it is essential to use normative values adapted for the age range when interpreting the results.

\section{Other Hormonal Replacements}

Most of the children treated for GHD in early childhood have multiple pituitary hormone deficiencies and therefore a strong emphasis should also be placed on substituting the other hormones. Thyroid hormone deficiency should be closely monitored when GH treatment is ini-

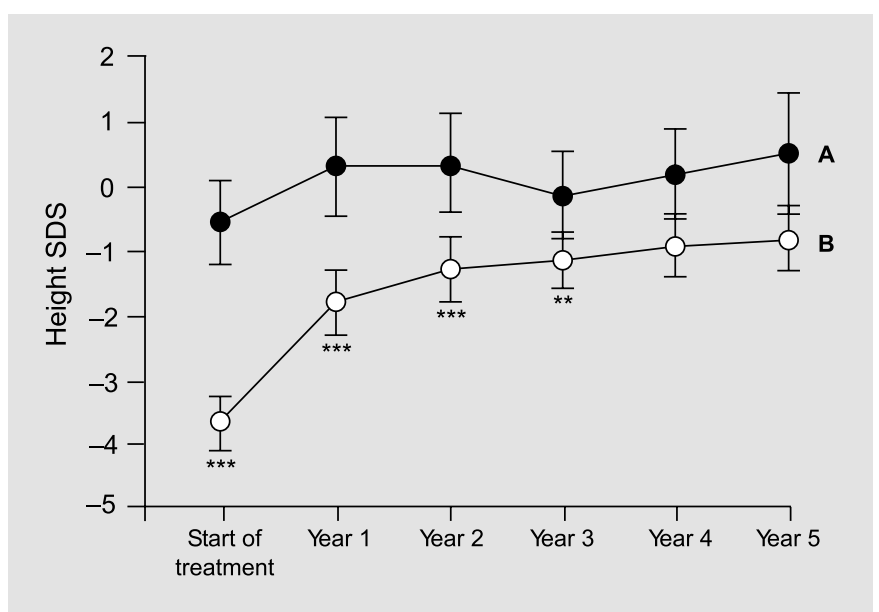

Fig. 4. Comparison of height SDS during 5 years of GH treatment between patients without (closed circles, A) and with (open circles, B) initial growth retardation. In each group, yearly changes, when statistically significant, are indicated $\left(* * \mathrm{p}<0.01,{ }^{* * *} \mathrm{p}<0.001\right)$. Values are mean \pm SD. Reproduced, with permission, from Rappaport et al. [14]: ${ }^{\odot}$ The Endocrine Society.

tiated because many children with low normal free thyroxine (fT4) and free triiodothyronine (fT3) values have central hypothyroidism. Thus, fT4 and fT3 levels should be monitored carefully after the initiation of $\mathrm{GH}$ treatment and patients treated with $L$-thyroxine should have the dosing adapted to obtain fT3 values in the normal reference range. Hydrocortisone replacement should be used in patients with adrenocorticotropic hormone deficiency, in view of the low daily production rate of cortisol, which averages $4-5 \mathrm{mg} / \mathrm{m}^{2}$, i.e. a few $\mathrm{mg}$ per day in children [21]. The use of physiological doses of hydrocortisone allows for beneficial effects on carbohydrate and liver metabolism [22], without deleterious effects on the growth profile [23]. Hormonal substitution in gonadotropin deficiency is a challenge that has so far been minimally addressed by physicians since, at present, testosterone is only administered to boys with micropenis [24]. Other aspects, however, should also be considered. First, infants have an active gonadotropic axis during the first year of life [25, 26], which should ideally be replaced in a physiological fashion. Second, during childhood, sex steroid secretion is not totally absent, but is below the limit of detection of most conventional assays [27]. Similarly, in children with precocious puberty treated with gonadotropin-releasing hormone agonists, growth is often markedly decreased, probably as a result of oestrogen levels being below physiological values and the addition of low doses of oestrogens improves growth velocity [28]. In theory, therefore, it 
would be of benefit to try to restore these low sex steroid levels. However, none of the pharmaceutical preparations currently available are adequate for this kind of approach. The most direct way of replacing gonadotropins is through the administration of the gonadotropins themselves, particularly in boys in whom fertility might be difficult to induce later in life because of early damage to the exocrine compartment of the testis. A pilot investigation has been undertaken by Skakkebaek and colleagues in Copenhagen [29], in which low doses of gonadotropins were used to increase both testicular size and inhibin B secretion. This approach seems attractive, but it will be a number of years before a result can be seen in terms of fertility.

The diagnosis and treatment of posterior pituitary dysfunction deserves a special mention. In a minority of patients, mostly those with septo-optic dysplasia, diabetes insipidus is evident at diagnosis and requires lifelong substitution therapy [30]. Less frequently, diabetes insipidus has been reported in the context of anterior pituitary hormone deficiency with transected pituitary stalk and absent or faint posterior pituitary signal [31, 32]. Of interest, Yamanaka et al. [33] systematically evaluated the urinary osmolality after water deprivation in 17 patients with an ectopic posterior pituitary gland and 3 patients without a detectable posterior pituitary. The patients with a small ectopic posterior pituitary gland had a lower urinary osmolality $(719 \pm 41 \mathrm{mOsm} / \mathrm{kg})$ than those with a large posterior pituitary $(1,086 \pm 53 \mathrm{mOsm} / \mathrm{kg})$ or normal pituitary magnetic resonance image $(1,002 \pm 41 \mathrm{mOsm} / \mathrm{kg})$. Similarly, arginine vasopressin (AVP) response to hypertonic saline infusion was lower in patients with a small ectopic posterior pituitary gland, indicating that these patients might have a 'partial' defect in their AVP secretion. Most patients in this study were, however, older than 5 years of age, and we have, on occasion, observed patients with apparent diabetes insipidus in the neonatal period who have normal neurohypophyseal function later in life. Therefore, diabetes insipidus should always be investigated in infants with congenital hypopituitarism and failure to thrive, despite the administration of anterior pituitary hormone replacement therapy.

\section{Long-Term Results Obtained in Very Young Children with GHD}

Long-term results of the outcome after early GH treatment have only appeared in recent years and so it is only now that the first results in children treated exclusively with recombinant GH can be analysed. De Luca et al. have reported the outcome in 13 patients treated with $\mathrm{GH}$ before the age of 5 years [34]. The patients reached a final height of $-0.9 \pm 1.7 \mathrm{SDS}$, compared with a parental target height of $-0.7 \pm 1.3$ SDS. In our own study, final height data are only available for 25 of the 59 patients described in table 1 . In males, adult height was $168 \pm$ $4 \mathrm{~cm}$, compared with a target height of $171 \pm 6 \mathrm{~cm}$, while in females, adult height was $156 \pm 7 \mathrm{~cm}$, compared with $160 \pm 5 \mathrm{~cm}$. In both sexes, the difference between target and adult height was not statistically significant. These results demonstrate that, even with the suboptimal GH regimens used when these patients were young, they reach, on average, a final height close to target height. It should be kept in mind that patients with untreated neonatal hypopituitarism have a very severe height deficit with average height around -3 to -5 SDS. These very favourable results of GH treatment in neonatal hypopituitarism are in marked contrast with those obtained in patients treated for GHD in the pre-pubertal period. In these cases, which represent the majority of patients currently treated for GHD, the growth benefit induced by GH therapy is very limited [35].

In conclusion, although tremendous progress has been made in the care of children with early onset and severe hypopituitarism, there is still a long way to go before we can say that their condition has been corrected. Careful assessments of the psychological and neurodevelopmental outcomes will be necessary to evaluate the 'final results' of currently used endocrine replacement therapies. 


\section{References}

1 Ogilvy-Stuart AL: Growth hormone deficiency (GHD) from birth to two years of age: diagnostic specifics of GHD during the early phase of life. Horm Res 2003;60(suppl 1):2-9.

2 Drake WM, Howell SJ, Monson JP, Shalet SM: Optimizing GH therapy in adults and children. Endocr Rev 2001;22:425-450.

3 MacGillivray MH, Blethen SL, Buchlis JG, Clopper RR, Sandberg DE, Conboy TA: Current dosing of growth hormone in children with growth hormone deficiency: how physiologic? Pediatrics 1998;102:527-530.

4 Pirazzoli P, Cacciari E, De Iasio R, Pittalis MC, Dallacasa P, Zucchini S, Gualandi S, Salardi S, David C, Boschi S: Developmental pattern of fetal growth hormone, insulin-like growth factor I, growth hormone binding protein and insulin-like growth factor binding protein-3. Arch Dis Child Fetal Neonatal Ed 1997; 77:F100-F104.

5 Kaplan SL, Grumbach MM, Shepard TH: The ontogenesis of human fetal hormones. I. Growth hormone and insulin. J Clin Invest 1972;51:3080-3093.

6 Ogilvy-Stuart AL, Hands SJ, Adcock CJ, Holly JM, Matthews DR, Mohamed-Ali V, Yudkin JS, Wilkinson AR, Dunger DB: Insulin, insulin-like growth factor I (IGF-I), IGF-binding protein-1, growth hormone, and feeding in the newborn. J Clin Endocrinol Metab 1998;83: 3550-3557.

7 Chanoine JP, Rebuffat E, Kahn A, Bergmann $\mathrm{P}$, Van Vliet G: Glucose, growth hormone, cortisol, and insulin responses to glucagon injection in normal infants, aged $0.5-12$ months. J Clin Endocrinol Metab 1995;80:3032-3035.

8 Quattrin T, Albini CH, Cara JF, Vandlen RL, Mills BJ, MacGillivray MH: Quantitation of urinary somatomedin- $\mathrm{C}$ and growth hormone in preterm and fullterm infants and normal children. J Clin Endocrinol Metab 1988;66: 792-797.

9 Ishikawa M, Yokoya S, Tachibana K, Hasegawa Y, Yasuda T, Tokuhiro E, Hashimoto Y, Tanaka T: Serum levels of 20-kilodalton human growth hormone $(\mathrm{GH})$ are parallel those of 22-kilodalton human GH in normal and short children. J Clin Endocrinol Metab 1999; 84:98-104.

10 Juul A, Dalgaard P, Blum WF, Bang P, Hall K, Michaelsen KF, Muller J, Skakkebaek NE: Serum levels of insulin-like growth factor (IGF)binding protein-3 (IGFBP-3) in healthy infants, children, and adolescents: the relation to IGF-I, IGF-II, IGFBP-1, IGFBP-2, age, sex, body mass index, and pubertal maturation. J Clin Endocrinol Metab 1995;80:2534-2542.

11 Lofqvist C, Andersson E, Gelander L, Rosberg S, Blum WF, Albertsson-Wikland K: Reference values for IGF-I throughout childhood and adolescence: a model that accounts simultaneously for the effect of gender, age, and puberty. J Clin Endocrinol Metab 2001;86:5870-5876.
12 Kawai N, Kanzaki S, Takano-Watou S, Tada C, Yamanaka Y, Miyata T, Oka M, Seino Y: Serum free insulin-like growth factor I (IGF-I), total IGF-I, and IGF-binding protein-3 concentrations in normal children and children with growth hormone deficiency. J Clin Endocrinol Metab 1999;84:82-89.

13 Huet F, Carel JC, Nivelon J-L, Chaussain JL: Long-term results of $\mathrm{GH}$ therapy in GH-deficient children treated before 1 year of age. Eur J Endocrinol 1999;140:29-34.

14 Rappaport R, Mugnier E, Limoni C, Crosnier H, Czernichow P, Leger J, Limal JM, Rochiccioli P, Soskin S: A 5-year prospective study of growth hormone $(\mathrm{GH})$-deficient children treated with $\mathrm{GH}$ before the age of 3 years. French Serono Study Group. J Clin Endocrinol Metab 1997;82:452-456.

15 Boersma B, Rikken B, Wit JM: Catch-up growth in early treated patients with growth hormone deficiency. Dutch Growth Hormone Working Group. Arch Dis Child 1995;72:427431

16 De Luca F, Arrigo T, Bozzola M, Crisafulli G, Ghizzoni L, Messina MF, Wasniewska M: Hypopituitarism during the first year of life. A collaborative Italian study. Arch Pediatr 1998;5: 313S-317S.

17 Hawdon JM: Hypoglycaemia and the neonatal brain. Eur J Pediatr 1999;158:S9-S12.

18 Cresto JC, Abdenur JP, Bergada I, Martino R: Long-term follow up of persistent hyperinsulinaemic hypoglycaemia of infancy. Arch Dis Child 1998;79:440-444.

19 Duvanel CB, Fawer CL, Cotting J, Hohlfeld P, Matthieu JM: Long-term effects of neonatal hypoglycemia on brain growth and psychomotor development in small-for-gestational-age preterm infants. J Pediatr 1999;134:492-498.

20 Souto I, Coutant R, Rouleau S, Limal JM: Continuous glucose monitoring system: a new tool for the diagnosis of hypoglycemia and growth hormone deficiency in infants. Horm Res 2002;58(suppl 2):103.

21 Brandon DD, Isabelle LM, Samuels MH, Kendall JW, Loriaux DL: Cortisol production rate measurement by stable isotope dilution using gas chromatography-negative ion chemical ionization mass spectrometry. Steroids 1999;64: 372-378.

22 Leblanc A, Odievre M, Hadchouel M, Gendrel D, Chaussain JL, Rappaport R: Neonatal cholestasis and hypoglycemia: possible role of cortisol deficiency. J Pediatr 1981;99:577-580.

23 Witz L, Josefsberg Z, Kaufman H, Laron Z: When should hydrocortisone therapy be instituted in children with hypopituitarism? Am J Dis Child 1988;142:881-883.
24 Bin-Abbas B, Conte FA, Grumbach MM, Kaplan SL: Congenital hypogonadotropic hypogonadism and micropenis: effect of testosterone treatment on adult penile size why sex reversal is not indicated. J Pediatr 1999;134: 579-583.

25 Quigley CA: The postnatal gonadotropin and sex steroid surge-insights from the androgen insensitivity syndrome. J Clin Endocrinol Metab 2002;87:24-28.

26 Bouvattier C, Carel JC, Lecointre C, David A Sultan C, Bertrand AM, Morel Y, Chaussain JL: Postnatal changes of T, LH, and FSH in 46, XY infants with mutations in the AR gene. J Clin Endocrinol Metab 2002;87:29-32.

27 Klein KO, Baron J, Colli MJ, McDonnell DP, Cutler GB Jr: Estrogen levels in childhood determined by an ultrasensitive recombinant cell bioassay. J Clin Invest 1994;94:24752480 .

28 Lampit M, Golander A, Guttmann H, Hochberg Z: Estrogen mini-dose replacement during GnRH agonist therapy in central precocious puberty: a pilot study. J Clin Endocrinol Metab 2002;87:687-690.

29 Main KM, Schmidt IM, Toppari J, Skakkebaek NE: Early postnatal treatment of hypogonadotropic hypogonadism with recombinant human FSH and LH. Eur J Endocrinol 2002;146:7579.

30 Traggiai C, Stanhope R: Endocrinopathies associated with midline cerebral and cranial malformations. J Pediatr 2002;140:252-255.

31 Yagi H, Nagashima K, Miyake H, Tamai S, Onigata K, Yutani S, Kuroume T: Familial congenital hypopituitarism with central diabetes insipidus. J Clin Endocrinol Metab 1994; 78:884-889.

32 Kikuchi K, Fujisawa I, Momoi T, Yamanaka C, Kaji M, Nakano Y, Konishi J, Mikawa H, Sudo M: Hypothalamic-pituitary function in growth hormone-deficient patients with pituitary stalk transection. J Clin Endocrinol Metab 1988;67:817-823.

33 Yamanaka C, Momoi T, Fujisawa I, Kikuchi K, Kaji M, Yorifuji T, Sasaki H, Sudo M, Konishi J, Mikawa H: Neurohypophyseal function of an ectopic posterior lobe in patients with growth hormone deficiency. Acta Endocrinol (Copenh) 1990;122:664-670.

34 De Luca F, Maghnie M, Arrigo T, Lombardo F, Messina MF, Bernasconi S: Final height outcome of growth hormone-deficient patients treated since less than five years of age. Acta Paediatr 1996;85:1167-1171.

35 Carel JC, Ecosse E, Nicolino M, Tauber M, Leger J, Cabrol S, Bastie-Sigeac I, Chaussain JL, Coste J: Adult height after long-term recombinant growth hormone treatment for idiopathic isolated growth hormone deficiency: observational follow-up study of the French population-based registry. BMJ 2002;325:70-73. 